\title{
26450 - TAKING AIM WITH THE TRIGGER TOOL: APPLICATION IN TARGETED POPULATIONS
}

\section{Jeff Granton MD, Claudio Martin, MD; Frank Min, MD; Mohit Bhutani, Ron Butler, MD; London Health Sciences Centre, London, ON, Canada}

INTRODUCTION: Traditional determination of an adverse event related to a medication was through incident reports or pharmacy interventions. By the 1990s computerized models were developed for detecting potential adverse drug events with the use of standard "triggers" identified in the patient's medical record. (1) This methodology was adapted, allowing trained reviewers to efficiently identify adverse drug events in the patient's chart and determine whether harm occurred as a result. (2) Further modification of this "trigger tool" allows capture of events beyond those associated with medications. Taking aim at specific patient populations may increase the effectiveness of identifying adverse events. Our hypothesis is by applying the modified "trigger tool" to charts of critical care unit patients with a low predicted chance of mortality who died will yield a higher incidence of adverse events when compared to randomly selected charts.

METHODS: After receiving ethics board approval, a retrospective chart review (April 1 2002 to March 31 2003) was carried out involving two tertiary intensive care units in London, Ontario. Two groups of charts were created, 1) randomly selected and 2) patients with a $<50 \%$ (using APACHE-II) predicted risk of death on admission who ultimately died. Two independent reviewers, who were blinded to group assignment, applied the modified "trigger tool" to each chart. Primary endpoints were the number of adverse events and the associated severity of harm. Data was analyzed using SPSS. Categorical variables were tested using Fischer's exact test, between group comparisons of continuous variables that were normally distributed were tested with the two sample ttest and the Mann-Whitney U test was used for continuous variables with non-normal distributions. A p-value $<0.05$ was considered significant.

RESULTS: Eighty two charts were generated for review. Four charts were excluded ( 2 in each group), leaving 35 charts reviewed in the low risk group and 43 in the random group. The sex and age were similar between groups. Random charts and those from patients with a low probability of death who died showed a mean adverse event per day of 0.12 and 0.21 respectively $(p=0.023)$. Futhermore, events associated with the greatest degree of harm occurred in the group with a low predicted chance of death who died (Table \#1).

DISCUSSION: Using the modified "trigger tool" when comparing random charts to those of patients with a $<50 \%$ predicted chance of death who died yielded an increased number of adverse events discovered per day in the latter group. Thus application to targeted populations may increase its effectiveness as a quality improvement and patient safety tool.

REFERENCES: 1) JAMA 1991, 266: 2847-51 2) Qual Saf Health Care 2003, 12: $194-$ 200 
Table w1

\begin{tabular}{|l|l|l|l|}
\hline & Random & $\begin{array}{l}\square 50 \% \text { Predicted } \\
\text { Chance of Death } \\
\text { Who Died }\end{array}$ & $\mathrm{p}$ value \\
\hline Number of Charts & 43 & 35 & \\
\hline Male & $24(55.8 \%)$ & $17(48.6 \%)$ & $\mathrm{P}=0.649^{*}$ \\
\hline Mean Age (years) & 59.1 & 61.2 & $\mathrm{p}=0.589^{* *}$ \\
\hline $\begin{array}{l}\text { Mean ICU } \\
\text { Length of Stay } \\
\text { (days) }\end{array}$ & 10.5 & 20.2 & $\mathrm{p}=0.190^{*}$ \\
\hline $\begin{array}{l}\text { Mean Number of } \\
\text { Adverse Events per } \\
\text { Day }\end{array}$ & 0.12 & 0.21 & $\mathrm{p}=\mathbf{0 . 0 2 3 ^ { * }}$ \\
\hline $\begin{array}{l}\text { Number of Adverse } \\
\text { Events Directly } \\
\text { Related to Death }\end{array}$ & 0 & 6 & $\mathrm{p}=\mathbf{0 . 0 0 6 *}$
\end{tabular}

- Fisher's exact test

** Two sample t-test

"Mann-Whitney U test 